\title{
medievalismo lúdico dos jogos de tabuleiro
}

The ludic medievalism of board games

Douglas Mota Xavier de Lima 
Resumo: A Idade Média tem mobilizado o interesse de diferentes gerações no mundo contemporâneo, estando amplamente presente na literatura, no cinema, nas séries de TV, nas histórias em quadrinhos e nos jogos, sejam eles jogos eletrônicos ou analógicos. Nesse sentido, o artigo analisa o medievalismo - entendido como a recepção da Idade Média no período pós-medieval - nos jogos de tabuleiro modernos. A seleção dos jogos foi realizada em dois sites relacionados com a temática, um internacional e outro brasileiro, e abarcou um conjunto de 20 jogos de tipo eurogames. Por meio dos jogos analisados, é possível reconhecer alguns indícios que remetem à representação da Idade Média nos jogos de tabuleiro, os quais formam um léxico visual que evoca a Idade Média presente no imaginário contemporâneo.

Palavras-chave: Idade Média; Medievalismol Jogos; Jogos de tabuleiro; Eurogames.

Abstract: The Middle Ages have mobilized the interest of different generations in the contemporary world, being widely present in literature, cinema, TV series, comic books and games, be they electronic or analog games. In this sense, the article analyzes the medievalismo - understood as the reception of the Middle Ages in the post-medieval period - in modern board games. The selection of games was held in two sites related to the theme, one international and the other Brazilian, and included a set of 20 Eurogames. Through the analyzed games it is possible to recognize some signs that refer to the representation of the Middle Ages in board games, which form a visual lexicon that evokes the MiddleAges presentin thecontemporaryimagination. Keywords: Middle Ages; Medievalism; Games; Board Games; Eurogames. 
Idade Média é o período histórico que se estende do fim do Império Romano Ocidental, no século V d.C., até a conquista de Constantinopla pelos turcootomanos (1453) ou a chegada de Colombo às Américas (1492). Em que pesem as inúmeras limitações implícitas a essa definição e as diversas propostas de redefini-la, ela serve de referência para a delimitação de dois objetos e dois eixos de investigação: o primeiro remete às sociedades inseridas nesse recorte temporal, assim como ao estudo dessas sociedades, eixo que pode ser definido como medievalística; o segundo, denominado medievalismo, tem como definição comum a representação, a recepção ou o uso pós-medieval da Idade Média europeia, bem como o estudo desses elementos. Os limites entre tais eixos investigativos são tênues, e é possível, inclusive, compreender a própria medievalística ou os estudos medievais como uma das muitas formas de recepção da cultura medieval nos tempos pós-medievais (EMERY, UTZ, 2014). De todo modo, a delimitação é útil para esclarecer que a presente reflexão se concentra no medievalismo, visando discutir determinada manifestação da recepção da Idade Média na contemporaneidade.

A recepção do medievo é diversa e pode abarcar expressões: literárias, que vão de Victor Hugo (Notre Dame de Paris - 1831) a Ariano Suassuna (O romance d'a pedra do reino e o príncipe do sangue do vai-e-volta - 1971) e George R. Martin (Crônicas de gelo e fogo - 1996-); cinematográficas, como o épico El Cid (1961) ou a animação Como treinar o seu dragão (2010); quadrinísticas, com Príncipe valente (1937) ou Camelot 3000 (1982); arquitetônicas, como a reconstrução do castelo de Guédelon, na França, ou a Basílica Menor de Nossa Senhora do Rosário de Fátima, em São Paulo; musicais, com o Viking Metal e a Celtic Music; e lúdicas, com Dungeons \& dragons (1974) e Age of empires (1997), ou festivais, com os banquetes e festas medievais espalhados por diferentes países, inclusive o Brasil; entre outros inúmeros exemplos.

O termo inglês medievalism tem origens no século XIX (MATTHEWS, 2015) e, desde o final do século passado, vem sendo usado como referência para o campo de estudos acerca da recepção da Idade Média. É no termo, por exemplo, que se estrutura a Society for the Study of Medievalism, fundada em 1976, e a principal publicação da área, a revista Studies in Medievalism, publicada desde 1979. Em francês, otermo médiévalisme também tem se afirmadogradualmentee orientado, por exemplo, as pesquisas da Association Modernités Médiévales, fundada em 2004 (FERRÉ, 2010). No Brasil, ainda não há uma definição terminológica, sendo expressão disso a diversidade de termos utilizados para tratar das recepções e dos usos do passado medieval, entendido como reminiscências medievais ou 
medievalidade (MACEDO, 2009), como ressurgências (NASCIMENTO, 2015) ou como medievalismo (PORTO JÚNIOR, 2018). Apesar disso, na última década observa-se o significativo crescimento do número de estudos e, inclusive, a formação de grupos de pesquisa relacionados com o tema, ${ }^{2}$ o que pode indicar o amadurecimento das abordagens, da terminologia e, quiçá, a constituição de um campo.

As pesquisas têm investigado diferentes manifestações do medievalismo e, permanecendo na proposta de delimitação, é possível estabelecer três amplos conjuntos de estudos: os usos políticos da Idade Média, em especial por grupos nacionalistas e conservadores (CARPEGNA FALCONIERI, 2015; ELLIOT, 2017); o recriacionismo histórico (historical reenactment ou living history), pensado tanto como instrumento educativo quanto como motivo turístico e econômico (CRAMER, 2014; WADA et al., 2014); e a recepção da Idade Média como motivo midiático, literário e lúdico (HAYDOCK, 2010; BESSON, KIKUCHI, TROADEC, 2014). O presente estudo se integra a essa terceira vertente, explorando o medievalismo lúdico dos jogos.

Desde o século passado, a Idade Média tem sido uma das principais fontes de inspiração para o universo dos jogos, tanto analógicos quanto digitais, em parte pelas repercussões da obra de J. R. R. Tolkien e C. S. Lewis, autores que definiram as bases da fantasia medieval. Juan Francisco Jiménez Alcázar (2016) lembra que não há período histórico que mexa tanto com o imaginário coletivo como o medieval, período que:

[...] representa em todo momento o intangível e o universo das mais irracionais crenças e comportamentos humanos. A bruxaria, a magia, a brutalidade, o amor cortês (o cavaleiro e a dama), o fantástico de uma arquitetura imaginada (castelos em ruínas contemplados nas mentes das pessoas do século XIX e, em consequência, nas nossas, homens e mulheres do século XXI) ou não (fortalezas esplêndidas que dominam a paisagem europeia), armas, sinal de dignidade (grandes espadas), heráldica e genealogia como atrativo por si...; a percepção de uma categoria e comportamento social (um senhor feudal tem hoje uma imagem coletiva muito bem definida, à margem de sua realidade, igual que um vassalo)... até a gastronomia possui um espaço nesse universo (um jantar medieval se associa a uma deglutição sem medida e gigantesca (JIMÉNEZ ALCÁZAR, 2016, p. 80). ${ }^{3}$ 
O tema do medievalismo nos jogos tem sido investigado, sobretudo, em duas vias: uma se refere aos jogos de encenação e interpretação de personagens (role-playing game - RPG) (ABIKIER, BESSON, PLET-NICOLAS, 2009; KLINE, 2016; VIVEIROS, 2017), os quais, geralmente, estão inseridos na dimensão da fantasia medieval, com ampla presença de seres fantásticos (trolls, orcs, elfos, dragões etc.) e elementos mágicos - vide Dungeons \& dragons, lançado em 1974 e considerado o fundador do RPG -, tendo como foco de investigação o aspecto participativo de tais jogos; outra via explora os jogos eletrônicos (videogames ou apenas games), modalidade de jogos que apresenta uma relação menos direta com a fantasia medieval, como é o caso de Age of empires (1997) e Kingdom come: deliverance (2018), e concentra-se, particularmente, na questão da simulação digital do passado medieval e nas implicações de tais jogos para o ensino e a aprendizagem (TRAXEL, 2008; JIMÉNEZ ALCÁZAR, 2016; BIRRO, 2019). Apesar da importância dessas vias, o presente artigo procura discutir outra dimensão dos jogos, os jogos de tabuleiro (board games).

Em que pese o crescimento das investigações acerca dos jogos de RPG, os estudos de jogos (game studies) têm sido desproporcionalmente concentrados nos jogos digitais, deixando os jogos analógicos à margem do campo (TORNER, TRAMMELL, WALDRON, 2016). Iniciativas como as publicações Analog Game Studies e Board Game Studies Journal vêm buscando promover as pesquisas acerca dos jogos analógicos, mas as lacunas ainda se impõem. Desse modo, tendo em vista a ausência de investigações acerca do medievalismo nos jogos de tabuleiro, ${ }^{5}$ o presente artigo propõe analisar a recepção da Idade Média nos jogos de tabuleiro modernos, com o objetivo de fomentar novas investigações acerca do medievalismo e de contribuir para as lacunas sobre os jogos analógicos.

\section{Metodologia}

Em virtude do significativo volume de jogos de tabuleiro relacionados com a Idade Média, para o mapeamento e a seleção dos jogos optou-se por dois sites. O primeiro foi o BoardGameGeek.com, referência mundial relacionada com tal universo e que conta com mais de 80 mil jogos cadastrados. Uma das categorias de classificação desenvolvidas pelo site é “Medieval”, definida da seguinte maneira: "Os jogos medievais costumam ter temas ou histórias ambientadas na Europa ou na Ásia, entre o século V (476, a queda do Império Romano Ocidental) e o século XVI (1492, o início da colonização ultramarina europeia.” ${ }^{6}$ A categoria tem 3.920 jogos indexados, e, a partir dela, selecionou- 
se entre os 25 jogos mais bem ranqueados quais foram publicados no Brasil, chegando-se a um total de 12 jogos.

Figura 1 - Fluxograma da seleção de jogos de tabuleiro de temática medieval nos sites de referência, abril de 2020

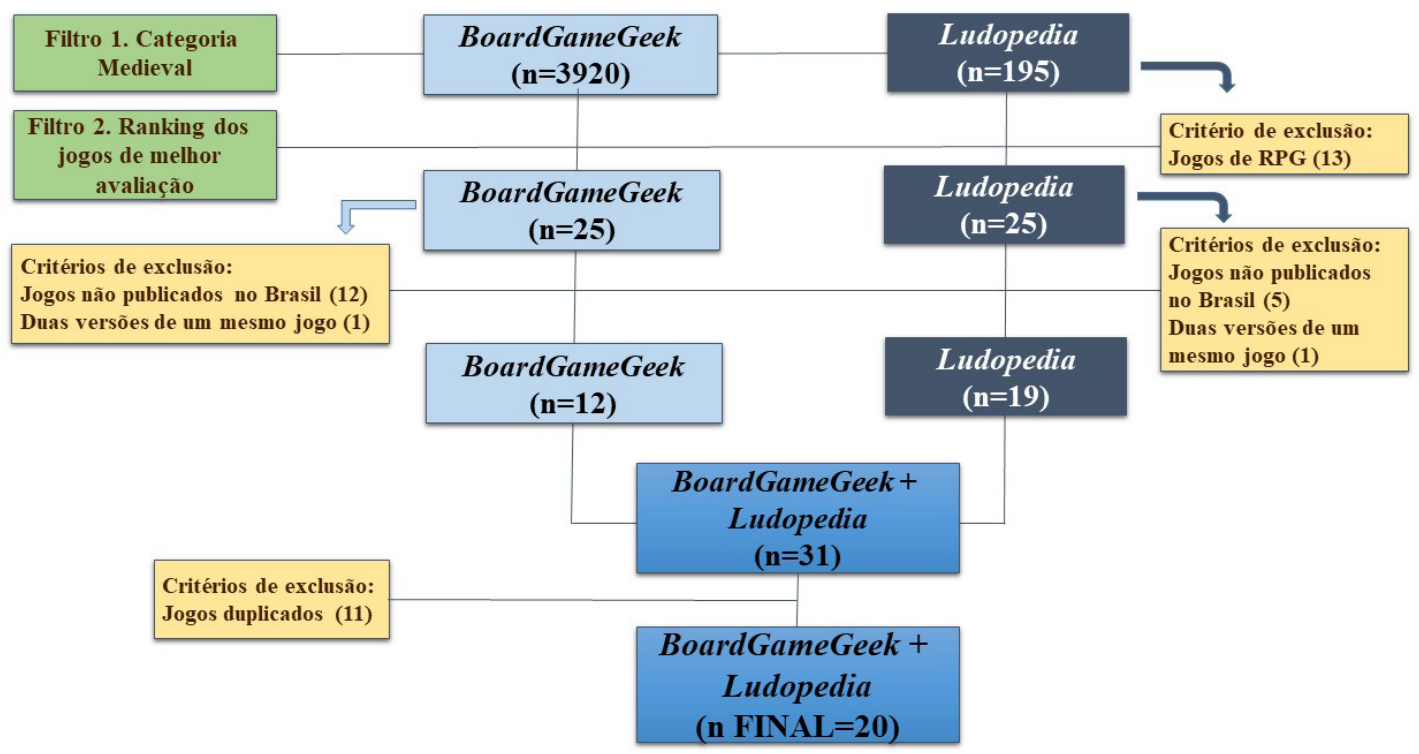

Fonte: Elaboração própria.

O mesmo procedimento foi aplicado ao site brasileiro Ludopedia.com.br, igualmente uma referência na temática e que tem mais de 2 mil jogos cadastrados. O site também oferece uma categoria de classificação “Medieval”, com 195 jogos indexados. ${ }^{8}$ Diferentemente do site anterior, neste não há definição dessa categoria, e essa circunstância resulta em uma diferença relevante entre os sites: em Ludopedia.com.br, os jogos indicados agregam tanto jogos de RPG quanto jogos de tabuleiro. Após a exclusão dos jogos RPG e permanecendo com o critério de selecionar apenas os 25 jogos mais bem ranqueados e publicados no Brasil, o total final foi de 19 jogos.

Ao realizar a junção de ambos os mapeamentos e a exclusão das repetições, chegou-se ao total de 20 jogos, os quais são descritos no Quadro 1.

Quadro 1 - Jogos de tabuleiro de temática medieval selecionados nos sites de referência, abril de 2020

\begin{tabular}{|c|c|c|}
\hline TÍTULOS EM POTUGUÊS & DESIGNER & ANO \\
\hline Carcassonne & Klaus-Jürgen Wrede & 2000 \\
\hline Agrícola & Uwe Rosenberg & 2007 \\
\hline
\end{tabular}




\begin{tabular}{|c|c|c|}
\hline Dominion & Donald Vaccarino & 2008 \\
\hline The castles of Burgundy & Stefan Feld & 2011 \\
\hline Village & Inka Brand e Markus Brand & 2011 \\
\hline Guerra do anel (segunda edição) & $\begin{array}{c}\text { Roberto Di Meglio, Marco Maggi e } \\
\text { Francesco Nepitello }\end{array}$ & 2012 \\
\hline Keyflower & Sebastian Breasdale e Richard Breese & 2012 \\
\hline Orléans & Reiner Stockhausen & 2014 \\
\hline Viagens de Marco Polo & Simone Luciani e Daniele Tascini & 2015 \\
\hline Invasores do Mar do Norte & Shem Phillips & 2015 \\
\hline Oh my goods! & Alexander Pfister & 2015 \\
\hline Zombicide: black plague & Raphaël Guiton, Jean-Baptiste Lullien e & 2015 \\
\hline Um banquete a Odin & Uwe Rosenberg & 2016 \\
\hline Kingdomino & Bruno Cathala & 2016 \\
\hline Charterstone & Jamey Stegmaier & 2017 \\
\hline Merlin & Stefan Feld e Michael Rieneck & 2017 \\
\hline Kingsburg (second edition) & Andrea Chiarvesio e Luca Iennaco & 2017 \\
\hline Sword \& sorcery: espíritos imortais & Simone Romano e Nunzio Surace & 2017 \\
\hline Arquitetos do reino ocidental & Shem Phillips e SJ Macdonald & 2018 \\
\hline Paladinos do reino ocidental & Shem Phillips e SJ Macdonald & 2019 \\
\hline
\end{tabular}

*Os jogos foram listados por ano, desconsiderando o ranking.

Fonte: Elaboração própria a partir dos rankings boardgamegeek.com e ludopedia.com.br.

Os jogos selecionados podem ser caracterizados como eurogames, uma das modalidades contemporâneas dos jogos de tabuleiro modernos. Assim, convém traçar, brevemente, as particularidades dessa tipologia e sua relação com a Idade Média. Em seguida, apresenta-se o material agrupando os jogos por meio de categorias temáticas referentes à recepção do medievo.

\section{Sobre jogos e jogos de tabuleiro modernos}

Os estudos de jogos, ludologia ou game studies, como são mais conhecidos, são um campo voltado à pesquisa de, ao menos, três dimensões relacionadas com o tema: os jogos em si, com suas mecânicas e regras; o jogar, isto é, a relação entre o jogo e o jogador; e a cultura, abarcando a relação entre o jogo e a sociedade no qual ele se insere. A partir dessa compreensão, percebe-se a amplitude do campo de pesquisa, que envolve áreas que vão desde a antropologia à ciência da computação. Desde o século passado, inúmeros autores se debruçaram 
sobre a definição de jogo, merecendo destaque nas ciências humanas autores como Johan Huizinga e Roger Caillois. Para os objetivos deste artigo, não serão aprofundadas as diferentes proposições do campo; antes, busca-se oferecer uma definição sobre os jogos e apresentar um panorama histórico dos jogos de tabuleiro.

Jesper Juul, ludologista dinamarquês, é um dos autores a propor uma definição de jogo. Partindo das definições de diferentes teóricos do tema, ele oferece uma proposta de síntese que estabelece seis características para definir os jogos:

1) Regras: jogos são baseados em regras. 2) Resultado variável e quantificável: jogos têm resultados variáveis e quantificáveis. 3) Valor atribuído aos resultados possíveis: os diferentes resultados potenciais do jogo recebem valores diferentes, alguns sendo positivos, alguns sendo negativos.4) Esforço do jogador: o jogador investe esforço para influenciar o resultado. (Ou seja, os jogos são desafiadores) 5) Jogador apegado ao resultado: jogadores estão apegados aos resultados do jogo no sentido de que um jogador será o vencedor e "feliz" se um resultado positivo acontecer, e perdedor e "infeliz" se acontecer um resultado negativo. 6) Consequências negociáveis: o mesmo jogo [conjunto de regras] pode ser jogado com ou sem consequências na vida real (JUUL, 2003, s/p.).

Ainda que ampla o suficiente para agregar esportes, jogos de tabuleiro e jogos eletrônicos, a proposição serve de orientação para a compreensão acerca de um objeto tão vasto como os jogos. Destarte, reforça-se o foco de análise para os jogos de tabuleiro, jogos que carregam suas particularidades em meio ao conjunto mais amplo dos jogos.

Existem vestígios que apontam para a presença de jogos de tabuleiro em tempos remotos, milênios antes da era comum. Esse é o caso, por exemplo, de Senet, Oware e do Jogo real de Ur, os mais antigos jogos de tabuleiro conhecidos. De todo modo, apenas a partir do século XX, com a industrialização e o avanço do processo de urbanização, por exemplo, ocorreu o estabelecimento de uma indústria dos jogos, com produções em massa, inaugurando a era dos jogos modernos. A principal expressão desses novos tempos é Monopoly (1935), inspirado no jogo The landlord's game (1903), e que já foi traduzido para mais de 40 idiomas (PALOMAR MILLÁN, 2012). Outro fator relevante a ser considerado 
é que foi no início do século XX que os jogos de tabuleiro começaram a ser produzidos para o entretenimento e o lazer, sendo gradativamente desprendidos da preocupação com os ensinamentos acadêmicos e morais, elemento marcante nos jogos do século XIX (WHITEHIL, 1992).

Ao longo das décadas seguintes, com a multiplicação das obras e dos gêneros disponíveis no mercado (jogos familiares, jogos de cartas, jogos de guerra, entre outros), os jogos passaram a ser classificados, sobretudo, pelo tema e pela mecânica. No entanto, para Stewart Woods, o atual cenário do mercado de jogos demanda outras classificações, reconhecendo que os jogos modernos são uma mercadoria manufaturada, projetada e publicada em um momento específico da história e produzida para um mercado particular e por razões essencialmente comerciais. Assim:

\begin{abstract}
A natureza de tais jogos é que eles são jogados por grupos específicos de pessoas e, assim, se prestam para o desenvolvimento de formações culturais que refletem o momento em que são produzidos e a identidade e opções de lazer dos jogadores. Este contexto histórico, cultural e econômico não pode ser ignorado ao se considerar qualquer categorização (WOODS, 2012, p. 17). ${ }^{11}$
\end{abstract}

Woods propõe distinguir três tipos principais de jogos de tabuleiro: classical game, mass-market game e hobby game. Classical game são jogos sem autoria atribuída e sem a reivindicação de patente por alguma empresa ou organização, sendo o xadrez um exemplo. Mass-market game relaciona-se com os jogos com proprietário definido, produzidos em massa e voltados para o público em geral, como Monopoly e Jogo da vida. Por fim, hobby game remete aos jogos surgidos a partir da segunda metade do século XX, desenvolvimento que ocorreu fora do mercado de massa e, consequentemente, fora da grande indústria dos jogos e direcionado a segmentos particulares da sociedade. Para o autor, essa última categoria pode ser dividida em quatro gêneros: wargames, role-playing games, collectible card games e eurogames (WOODS, 2012).

Desde os anos 1980, a indústria europeia de jogos foi revitalizada, mobilizando a promoção de novos jogos e novos designers, sendo expressão desse movimento a feira internacional de jogos que ocorre anualmente em Essen, na Alemanha, desde 1983, e que estabelece o prêmio Spiel des Jahres aos melhores jogos de cada ano. Em meio a esse processo, sobretudo nos anos 1990, os eurogames (ou jogos de estilo alemão) se desenvolveram e reorientaram o mercado mundial 
de jogos de tabuleiro, sendo The settlers of Catan (1995), de Klaus Teuber, o principal exemplo desse novo gênero.

Em linhas gerais, os estudos estabelecem um contraste entre os eurogames e os american games ${ }^{12}$ - mais voltados ao tema da guerra, da disputa direta entre os participantes e da sorte. Sem a intenção de aprofundar as diferenças entre as vertentes, destaca-se apenas que, enquanto os american games tenderam a concentrar-se no tema dos conflitos militares do século XX, especialmente na Segunda Guerra Mundial, os eurogames têm explorado amplamente as Idades Antiga, Medieval e Moderna como temáticas para os jogos. Para Timothy Miller, além do apelo exercido pela Idade Média, esse aspecto se explica pelos fatores comerciais:

Em parte, a Idade Média se tornou um cenário tão popular para designers de jogos pela simples razão de que ninguém é dono do Rei Arthur, por assim dizer. Como uma espécie de "megatexto" de domínio público, cenários medievais e histórias como as lendas arturianas vêm com reconhecimento de consumidor embutido gratuito em um mercado onde licenças lucrativas para os direitos de fazer jogos vinculados a franquias de mídia populares são extremamente caras, mas ferozmente disputadas, especialmente propriedades marcantes como Star Wars, Star Trek, O Senhor dos Anéis, Game of Thrones e os super-heróis da Marvel e da DC, além de qualquer número de propriedades menos importantes (MILLER, 2019, p. 155). ${ }^{1.3}$

As características mais comuns dos eurogames são: regras simples e explicadas em poucas páginas; os jogadores tendem a jogar até o final e não serem eliminados durante o jogo; ênfase na estratégia e na competitividade; alto padrão de qualidade das peças, da arte e do tabuleiro; mais destaque à mecânica do que ao tema; diversidade de mecânicas; limitação do fator sorte/ azar; pouco uso de dados; privilégio aos conflitos indiretos em vez de aos diretos entre os jogadores; tempo de jogo previsível (WOODS, 2012; PALOMAR MILLÁN, 2012).

A partir desse revigoramento dos jogos, observa-se o significativo crescimento do mercado. Em 2018, por exemplo, foram lançados mais de 4 mil jogos de tabuleiro no mundo e centenas no Brasil. ${ }^{14}$ No mesmo ano, as estimativas apontam que o mercado brasileiro envolveu cerca de 700 milhões de reais, e projeta-se que, até 2023, poderá girar em torno de 12 bilhões de dólares e ter um crescimento médio anual de $9 \%$. O mercado dos jogos de tabuleiro é 
dominado por grandes editoras internacionais, como Hasbro, Asmodee Editions, Ravensburger, Fantasy Flight Games, Kosmos e Cmon, e brasileiras, como Grow, Devir, Conclave e Galápagos Jogos, sendo também composto por inúmeros editores independentes e amadores que atuam, principalmente, pelo prazer do jogo. Cabe ainda considerar que esse mercado vai além das editoras e dos jogos em si, envolvendo acessórios, eventos, casas temáticas etc. Apesar disso, um dos empecilhos do mercado é o preço dos jogos, que costumam custar entre R \$ 100,00 e $\mathrm{R} \$ 400,00$ reais cada.

Com base nos elementos expostos, pode-se afirmar que os jogos de tabuleiro que abordam a Idade Média são jogos modernos, de entretenimento, comerciais, voltados a públicos específicos e, em grande parte, caracterizados como eurogames. Esses jogos são resultado da convergência de diferentes aspectos de outros tipos de jogos, como os jogos de guerra e os jogos de RPG de fantasia, formando, dessa maneira, um terreno tão amplo e variado quanto a própria cultura dos jogos de tabuleiro (MILLER, 2019).

A caracterização dos jogos selecionados como eurogames é fundamental como ponto de partida, pois oferece ao menos uma chave de leitura que perpassará os apontamentos a seguir: a questão de esses jogos de tabuleiro terem propensão à abstração temática, com maior foco na mecânica. Esse fator tende a reduzir consideravelmente a profundidade temática e a imersão histórica desse tipo de jogo; porém, como se objetiva demonstrar, ele não exclui a necessidade de questionar qual abstração está sendo proposta por tais jogos.

Nessa perspectiva, alguns estudos têm investigado como os eurogames abordam questões como a experiência imperialista e colonial (BORIT, BORIT, OLSEN, 2018; MASTEY, 2019) e promovem uma abstração orientalizante (ROBINSON, 2016). Em diálogo com essas problemáticas, Bruno Faidutti argumenta acerca do "historical exoticism" dos jogos de tabuleiro:

A ideia fantasiosa que temos de alguns períodos históricos não é muito diferente da ideia fantasiosa que temos, ou tivemos, de outras partes do mundo. Os tempos distantes são como os lugares distantes - ingênuos, simples, vagamente perversos e, claro, reversos. [...] Embora o orientalismo puro como descrito por Said esteja provavelmente retrocedendo, ou pelo menos seja dissecado e discutido nas universidades, o exotismo histórico ainda é forte, principalmente porque não pode haver reação "pósmedievalista" ou "pós-antiquista" como houve a pós-colonial. [...] Então a verdadeira questão não é o orientalismo, mas o 
exotismo como um todo, na geografia e na história, e por que ele é tão prevalente nos jogos de tabuleiro, muito mais do que nos livros ou no cinema, muito mais do que nos videogames, e assim insistentemente nada sutil. [...] Para o game designer, Índia ou China, Idade Média ou Antiguidade, não são lugares geográficos ou tempos históricos, são apenas topoi, conjuntos de referênciaspadrão, que não devem ser mais sofisticados do que os dominados pelo jogador. [...] Como resultado, ele faz uso pesado de clichês orientalistas, "medievalistas" ou "antiquistas" (FAIDUTTI, 2017, p. 27-29). ${ }^{1}$

Com base nesse prisma de análise, convém questionar qual Idade Média está sendo abstraída nos jogos de tabuleiro e quais clichês medievalizantes são recorrentes.

\section{As múltiplas Idades Médias dos jogos de tabuleiro}

A Idade Média não existe. [...] é uma fabricação, uma construção, um mito, quer dizer, um conjunto de representações e de imagens em perpétuo movimento, amplamente difundidas na sociedade, de geração em geração... (AMALVI, 2006, p. 537).

Partindo dos apontamentos de Amalvi, convém situar a historicidade e os usos da expressão Idade Média ao longo do tempo. Em linhas gerais, a historiografia tem sido consensual em afirmar que foi no contexto do humanismo italiano, entre os séculos XIV e XV, que a expressão Medium Aevum e outros correlatos foram inicialmente utilizados para diferenciar a nova época dos tempos anteriores. Todavia, foi nos séculos seguintes, em especial a partir do século XVII, que ocorreu a afirmação da expressão Idade Média, entendida como idade histórica e associada às noções de tempo intermédio e obscuro. Com a terminologia definida, o século XVIII, anticlerical e antiaristocrático, acentuou o desprezo pela Idade Média, generalizando a assimilação entre Idade Média e obscurantismo, uma Idade das Trevas, e a expressão passa a ser compreendida como contraponto à sociedade burguesa em formação.

Nessa cronologia, o século XIX ocupa lugar de destaque. Nele se desenvolveu a medievalística, com a organização de arquivos, institutos de pesquisa, publicação de estudos etc., e o medievalismo, deveras associado à visão romântica da Idade Média. A partir dessa dupla orientação, podem- 
se compreender os múltiplos olhares sobre o medievo nos séculos XX e XXI, recepções que sobrepõem dados históricos com referências da cultura de massa e todo o universo de seres fantásticos. Essas diferentes maneiras de representar a Idade Média apresentam-se nos jogos de tabuleiro modernos. A seguir, expõem-se alguns eixos de problematização.

\section{A Idade Média como pretexto}

Ao tratar dos dez modos de sonhar a Idade Média, Umberto Eco propôs como primeira tipologia "A Idade Média como maneira e pretexto" (ECO, 1989, p. 80). Para o autor, nesse modo não existe real interesse pela época medieval, sendo ela vivida como lugar mitológico. A tipologia é útil para caracterizar, de certa maneira, todo o conjunto de jogos selecionados, posto que o apelo medieval nos jogos de tabuleiro sustenta-se, sobretudo, no potencial mercadológico do período, associado ao "exotismo histórico" pelo qual, comumente, a Idade Média é representada. De todo modo, um primeiro conjunto de jogos selecionados apresenta maior relação com a tipologia de Eco, visto que neles a Idade Média aparece apenas como inspiração temática, ao passo que o elemento de destaque fica na mecânica do jogo.

O primeiro exemplo é o célebre jogo Carcassonne (2000), ganhador do prêmio

Figura 2 - Capa do jogo Carcassonne e de uma de suas expansões
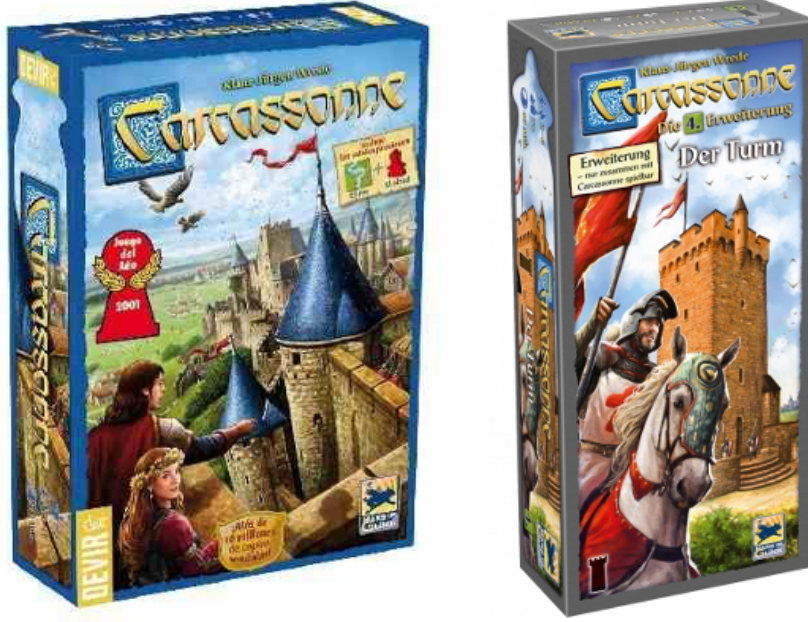

Fonte: https://www.ludopedia.com.br/jogo/ carcassonne? $\mathrm{v}=$ imagens, acesso em 16/05/2020.
Spiel des Jahres de jogo do ano em 2001 e que vendeu mais de 10 milhões de cópias desde o seu lançamento. Apesar de comumente classificado como "medieval", o manual do jogo não explicita essa referência, apenas explicando brevemente a história da cidade desde o século VI a.C. até os dias atuais e indicando que os jogadores atuarão "nesse incrível cenário histórico”. Desse modo, a definição como medieval sustenta-se pela iconografia e pela associação entre os 
elementos do jogo: a cidade amuralhada de Carcassonne, no sul da França, usada na capa e como mote do jogo (Figura 2); a ampla presença de campos ao redor das cidades, com mosteiros dispersos; a construção de cidades amuralhadas como uma das ações do jogo; a caracterização dos meeples, ${ }^{17}$ como monges e cavaleiros. $\mathrm{O}$ jogo tem inúmeras expansões que podem ser acrescentadas ao jogo-base, e em algumas delas, como a expansão Torres (2006), há claramente a mobilização da iconografia da cavalaria medieval, apesar de a jogabilidade e as orientações não envolverem nenhum aspecto do medievo.

O mesmo processo ocorre em Keyflower (2012) e Kingdomino (2016). Em ambos, os manuais não trazem qualquer referência temporal aos séculos medievais e nem exploram referências iconográficas do período, como feito em Carcassonne. Keyflower é o sétimo jogo de uma série da R\&D Games com jogos definidos na terra medieval "Key”, mas o vínculo com o medievo explicase, possivelmente, pelo ambiente rural, por casas de madeira e igrejas. Em Kingdomino, a referência ao medievo sustenta-se pelo fato de cada jogador ser um nobre tentando aumentar os domínios de seu reino, pela imagem de um castelo na capa do jogo e, novamente, pelo ambiente rural.

A referência à realeza e ao ambiente rural para orientar a classificação de um jogo como "medieval" fica evidente em Oh my goods! (2016), Charterstone (2017) e Agricola (2007). O primeiro jogo tem como enredo o reino fictício de Longsdale, indicando que se passa em finais da Idade Média. Não há outras referências ao medievo, porém Oh my goods! valoriza a ambientação rural, as roupas camponesas, a rusticidade dos edifícios e tem como elemento central a produção local, posto que cada jogador assume a função de um trabalhador na produção de bens (barris, ferro, tijolos, vidro, alimentos, roupas e outros), decidindo o que, quando e como produzir. Assim como o anterior, Charterstone se passa no fictício reino de Greengully, governado pelo rei Eterno, que decreta que os cidadãos devem colonizar novas terras. Não há referências temporais ou espaciais que vinculem o jogo ao medievo, e inclusive os elementos imagéticos do jogo afastam essa relação, seja na representação dos edifícios (casas, mercado, tesouro e tribuna) com traços modernos, seja na inclusão de um zepelim no tabuleiro. Contudo, a classificação do jogo como medieval parece se sustentar na referência ao reino e no fato de os jogadores serem colonos de um vilarejo. O terceiro jogo, Agricola, é um caso igualmente curioso, posto que o manual do jogo deixa explícito que ele se passa no século XVII, mais precisamente em 1670. Mesmo com essa referência, Agricola está classificado como "medieval”, ${ }^{18}$ e possivelmente essa classificação decorre de o jogo ter na figura do camponês e no cultivo dos campos seus elementos estruturantes. 
Village (2007) também é um caso peculiar, que, por caminhos diversos, pode ser inserido na categoria. Em parte, o jogo oferece imersão temática, mas não reivindica explicitamente tal elemento como "medieval", sendo essa uma abstração fomentada no jogador. O manual introduz o jogo da seguinte maneira:

A vida nessa Vila é muito difícil. Mas, ao menos, ela proporciona aos seus moradores oportunidades distintas de crescimento. Por exemplo: alguns moradores fazem sua carreira profissional na Câmara do Conselho, alguns no Mosteiro, enquanto que outros decidem virar viajantes e saem para conhecer o mundo... No jogo, cada jogador controla o destino de uma família e deseja levar a sua família a notoriedade. Mas nunca se esqueça da coisa mais importante: o tempo nunca para e, eventualmente, os membros da família passam dessa para melhor. Os moradores que deram o seu melhor e trabalharam duro durante a vida podem vir a ser imortalizados na história da Vila e, consequentemente, seus feitos aumentam a fama de sua família (BRAND, BRAND, 2007, p. 2).

Apesar de classificado como "medieval", em nenhum momento do manual o jogo se apresenta como tal ou oferece indicação cronológica nesse sentido. Não obstante, reivindicando o olhar de pesquisador medievalista, é possível afirmar que Village traz uma série de elementos históricos da sociedade do Ocidente medieval, como: as corporações, que requerem tempo e exclusividade para determinada produção

e para a aprendizagem do

Figura 3 - Tabuleiro do jogo Village ofício; a viagem para fora da vila como uma ação que propicia conhecimento e prestígio; a atuação na Câmara e no Mosteiro como ações que geram influência da família; a importância das gerações da família para garantir o prestígio da linhagem; a presença do livro dos registros para preservar a história e os feitos dos membros mais notáveis da vila etc. (Figura 3). Apesar disso, quiçá esses apontamentos sejam

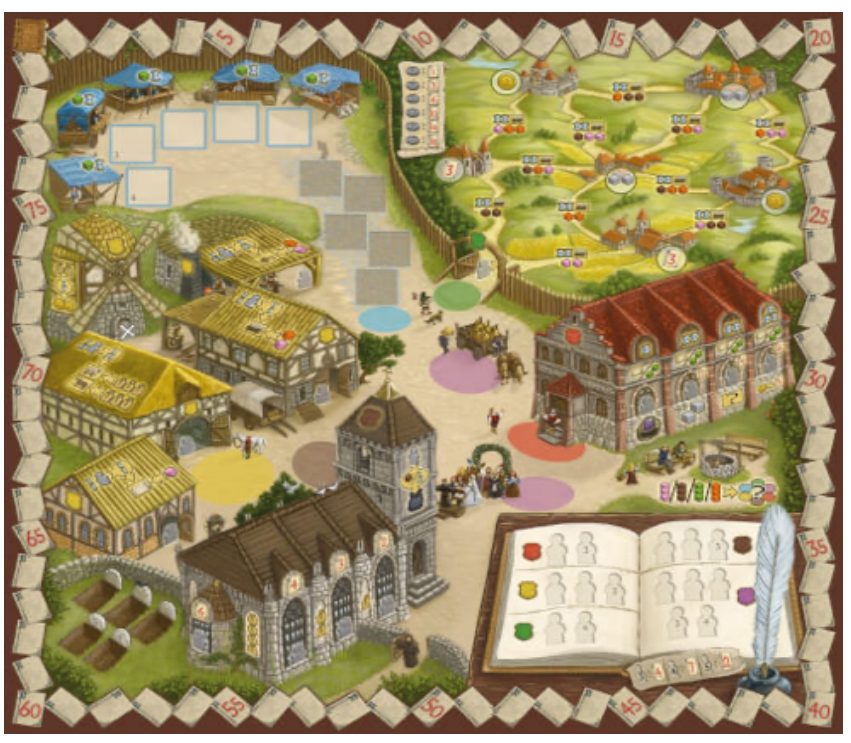

Fonte: https://www.ludopedia.com.br/jogo/ village?v=imagens, acesso em 16/05/2020. 
apenas a ressonância da ludicidade do jogo em um medievalista, expressão das heterotopias oferecidas pelos jogos de tabuleiro modernos (WILSON, 2017).

$\mathrm{O}$ fato é que, considerando textos e imagens, Village se passa em um tempo incerto e claramente distinto da sociedade urbana e industrial, em um vilarejo fictício, rústico, onde os jogadores podem exercitar a imaginação desenvolvendo suas famílias. Desse modo, a caracterização de Village como um jogo de temática medieval sustenta-se, sobretudo, na incorporação dos topoi recorrentes no universo dos jogos de tabuleiro - por exemplo, o destaque ao trabalho rural no tabuleiro do jogador, os trajes dos personagens da capa do jogo e a iconografia em geral.

\begin{abstract}
Você é um monarca, assim como seus pais antes de você, um governante de um pequeno e agradável reino, de rios e verdes jardins. Diferentemente de seus pais, no entanto, você tem desejos... e sonhos! Você quer um reino maior, mais encantador, com mais rios e uma quantidade ainda maior de diferentes árvores. Você quer um Dominion! Em todas as direções se veem feudos, terras livres e aristocratas. Todos são pequenas porções de terra, controladas por pequenos senhores e à beira da anarquia. Você trará civilização a este povo, unindo-os sob seu estandarte (VACCARINO, 2008).
\end{abstract}

Essa é a introdução do jogo Dominion (2008), único card game da lista. Ele é um jogo de construção de deck de cartas, e a proposta é que, durante a partida, os jogadores possam ir aprimorando seus decks. Apesar de não oferecer recortes espaciais e cronológicos, no trecho fica evidente a referência do jogo ao universo da nobreza medieval, aos feudos e, inclusive, à noção de anarquia feudal. Contudo, ao longo do jogo a Idade Média funciona apenas como um pano de fundo histórico, e a mecânica prevalece. A temática medieval aparece com mais destaque apenas nas imagens das cartas de Reino, ainda assim de maneira muito superficial e sem vinculação com o texto das cartas.

O último jogo nessa categoria é The castles of Burgundy (2011). Do aclamado designer alemão Stefan Feld, o jogo já foi o primeiro colocado no ranking geral de jogos da BoardGameGeek.com e ainda configura como um dos melhores jogos de todos os tempos. Ele se passa na região da Borgonha, especificamente no Vale do Loire, no século XV. Cada jogador assume o papel de um aristocrata, controlando um pequeno principado, onde pode construir assentamentos e 
castelos, praticar comércio ao longo do rio, explorar minas de prata e usar o conhecimento de viajantes. Mesmo com a vinculação temporal, o jogo dá pouco espaço para a temática e pouco explora a iconografia medieval, centrando-se na mecânica, particularmente a rolagem de dados e a colocação de peças.

Por meio dos jogos sistematizados nessa primeira categoria, é possível evidenciar que a caracterização de um jogo como “medieval” pode ser reivindicada pelo próprio jogo ou resultado de uma classificação posterior, feita pelo mercado e pelos consumidores. Independentemente da origem, a categoria "medieval" sustenta-se em um léxico visual comum, que compartilha referências com uma longa tradição intertextual acerca da Idade Média, uma espécie de guia que oferece coordenadas medievalizantes, em particular acerca do Ocidente medieval. Esse léxico medieval tem como pilares o meio rural, as pequenas cidades e o universo cavaleiresco, e, conforme os apontamentos de Faidutti (2017), revela um olhar nostálgico e romântico para o passado, manifesto tanto na escolha do tema quanto no estilo gráfico.

\section{A Idade Média no mundo secundário}

No cinema, nos quadrinhos, nas livrarias, a Idade Média conhece grande sucesso, sendo uma das manifestações mais importantes, sem dúvida, a explosão da fantasia, um subgênero bastante recente que na maioria das vezes desenvolve seus personagens em um universo imaginário próximo, ou pelo menos inspirado, na Idade Média. [...] Nesse reino de mundos que não existem, o leitor se depara com uma Idade Média que não existe, ou melhor, com uma miragem. [...] Gênero com fronteiras incertas e, dependendo das obras, no limite do literário e do paraliterário, a fantasia oferece um corpus que permite de forma privilegiada examinar essa oscilação entre a representação de uma Idade Média sonhada e revisitada e a convocação, às vezes, de um verdadeiro conhecimento erudito (ROCHEBOUET, SALAMON, 2008, p. 320).

A fim de compreender o lugar da Idade Média na fantasia, Anne Rochebouet e Anne Salomon discutem dois elementos: a tradição intertextual e a reutilização dos estereótipos. Argumentam que a presença do medievo no gênero segue, por um lado, uma lógica genealógica tributária da obra de J. R. R. Tolkien e, por outro, uma estética da repetição, que constrói um conjunto de elementos 
estereotipados que garantem familiaridade entre as obras. Do mesmo modo, pode-se afirmar que, em sua relação com a Idade Média, o medievalismo da fantasia acaba por ser "não um sonho da Idade Média, mas um sonho do medievalismo de outra pessoa. É o medievalismo dobrado sobre si mesmo" (KAUFMAN, 2010, p. 4). ${ }^{20}$ Nesse sentido, trata-se de um processo complexo de recepção e reinterpretação não somente de Tolkien, mas de uma gama mais vasta de medievalismos, recepção que se apresenta no universo dos jogos, em especial em Dungeons \& dragons.

A proposição de Kaufman aponta para a diferenciação entre medievalismo (medievalism) e neomedievalismo (neomedievalism), compreendendo que o segundo remete a um universo alternativo, um subconjunto funcional, historicamente contingente ao próprio medievalismo. Para a autora:

\begin{abstract}
Se pode-se dizer que o medievalismo funciona dentro de uma estrutura de distância (referencial ou não), então o neomedievalismo oblitera a distância em uma combinação intensificada de amor e aversão, desejo pelo passado dividido entre a negação da história e um desejo de retorno. [...] $\mathrm{O}$ neomedievalismo encontra uma forma de se agarrar ao passado rejeitando a "história", a alteridade, o tempo e o espaço que o separaram de seu objeto desejado, trazendo-o para o presente. Mas o que inicialmente parece ser a negação da história pelo neomedievalismo pode, em vez disso, ser um desejo pela história ao lado da desconfortável suspeita de que tal coisa não existe. $\mathrm{O}$ neomedievalismo consome a Idade Média em tropos fragmentados e repetitivos como forma de proteção contra perdas (KAUFMAN, 2010, p. 2-3).
\end{abstract}

Nesses termos, o neomedievalismo distorce a Idade Média de maneira intencional, expressando uma história maleável e pós-moderna, que, por vezes, homogeneíza o que seleciona do passado, fazendo com que todo o medievo seja absorvido em sua noção ocidental, com castelos, cavaleiros, damas e a espiritualidade cristã.

A herança multifacetada de Tolkien e da alta fantasia está evidente em Guerra do anel (2012), jogo baseado na trilogia $O$ senhor dos anéis, que se passa na Terra Média, onde os jogadores tomam parte na luta entre os exércitos dos povos livres e os membros da Sociedade do Anel contra as hordas de Saruman e Sauron; e em Sword \& sorcery (2017), jogo de tabuleiro cooperativo 
que combina elementos de diferentes variantes do RPG em uma aventura de fantasia épica, na qual cada jogador representa um herói (elfos, homens e anões) que foi convocado do mundo dos mortos para lutar contra as forças do mal (orcs, gremlins, trolls e assassinos) presentes no território fictício do Costa do Esporão. Ambos os jogos se enquadram na constante adaptação do universo da fantasia, um medievalismo do medievalismo, um neomedievalismo carregado de referências medievais que constituem elementos intrínsecos ao gênero e compõem um universo de seres fantásticos e monstros.

Paralelo a essa herança, mas com suas singularidades, outro jogo, Zombicide: black plague (2015), oscila em sua representação da Idade Média, sobrepondo o medievo fantástico ao erudito, para usar os termos de Anne Rochebouet e Anne Salomon (2008). Jogo cooperativo de temática zumbi, Black plague é uma versão do jogo original e se passa no medievo. Ele foi resultado de uma das campanhas mais bem-sucedidas de financiamento coletivo do site Kickstarter. com, alcançando 20.915 patrocinadores e $\$ 4.079 .204$ em recursos.

Aintroduçãodomanualdojogador explicita a vinculação como período:"Entre na Idade Média. Injustiça, guerras, pragas, mortes... Estamos acostumados com tudo isso, mas nada se compara a eles: os zumbis!" (GUITON, LULLIEN, RAOULT, 2015, p. 5). Pelo trecho, percebe-se a referência à Idade Média como época de barbárie, violência generalizada, doenças, contraponto da modernidade, uma Idade Média como "lugar bárbaro", para usar outra tipologia de Eco (1989). Essa perspectiva, por mais que seja alimentada pelas representações do medievo na cultura de massa, tem raízes no saber erudito e atesta as fronteiras fluidas da fantasia nos jogos. Zombicide: black plague mantém a temática zumbi que caracteriza a série, mas, ao situar o enredo do jogo na Idade Média, acrescenta a figura do necromante, de feitiços e encantamentos, associados a uma série de outros elementos que reforçam a identidade medieval do jogo, como armas (adaga, espada, besta, machado, flechas etc.), armaduras, menções aos castelos e à realeza, além da própria caracterização dos heróis (cavaleiro, elfo, mago, ferreiro, freira). Destarte, o jogo constrói sua própria Idade Média, um medievo exótico, compartilhado pelos jogadores, coerente em si mesmo, resultado tanto da reivindicação da visão de Idade Média amplamente enraizada na cultura erudita e popular ocidental quanto do mergulho no medievalismo da fantasia.

A percepção das fronteiras tênues entre o medievo histórico e o medievo fantástico nos jogos também pode ser observada em Kingsburg (2017). A ambientação do jogo em um reino é retomada, e cada jogador é um governante selecionado pelo rei para supervisionar os territórios recém-conquistados nos 
limites do reino. Não há referência cronológica. A iconografia do jogo sustentase na Idade Média ocidental, particularmente no universo aristocrático e citadino, com imagens de castelos, símbolos heráldicos, guildas, universidades e, principalmente, da corte régia, representada pelos reis e por seus 16 conselheiros. Apesar da prevalência de elementos factíveis da sociedade medieval, o jogo reafirma a maleabilidade da Idade Média lúdica, como na inserção dos inimigos a serem enfrentados pelos jogadores: bárbaros, goblins, zumbis, orcs, demônios e dragões. Por essas características, Kingsburg está fora da alta fantasia, do mundo alternativo, sendo uma expressão da baixa fantasia no universo dos jogos de tabuleiro, posto que estrutura sua aventura no mundo real, ainda que envolto em elementos mágicos.

Saindo do âmbito da fantasia, o mundo secundário, convém considerar três jogos que expressam referências de longa duração do medievalismo, particularmente com raízes no Romantismo do século XIX, e que têm sido constantemente revisitadas pelas mídias contemporâneas: Merlin (2017), Invasores do mar do Norte (2015) e Um banquete a Odin (2016).

\section{Nos tempos do rei Artur}

Herói mítico do período medieval, Artur é personagem central do campo literário chamado Matéria da Bretanha, conjunto de relatos que remontam ao século XII e agregam elementos como a Távola Redonda, o Santo Graal, a espada mágica Excalibur e personagens como Merlin, Percival, Tristão e Lancelot. O mito arturiano foi explorado nos séculos medievais, mas foi com o Romantismo oitocentista e, principalmente, com a cultura de massa do século XX que o mítico rei medieval teve seu prestígio reafirmado e passou a constituir uma peça-chave para a compreensão da recepção da Idade Média no mundo contemporâneo.

Nas últimas décadas, a Matéria da Bretanha tem sido constantemente revisitada, como no cinema e na Tv, com a superprodução Rei Arthur (2004), a série As aventuras de Merlin (2008) e o filme infantil O menino que queria ser rei (2019); e na literatura, com as traduções das obras de Bernard Cornwell, como a As crônicas de Arthur (1995-1997). Nos jogos de tabuleiro, o apelo arturiano também se manifesta, sendo possível observar o significativo crescimento da temática nas últimas décadas. Com base nos dados do site Boardgamegeek.com, constam 20 jogos relacionados com os termos "Arthur", "Merlin”, "Excalibur” publicados no século XXI. 
Diferentemente de filmes como Rei Arthur (2004), que buscaram "o homem por detrás da lenda”, ou dos jogos anteriormente caracterizados por usar a Idade Média como pretexto, dando mais ênfase à mecânica do que ao tema, em Merlin (2017), sem dispensar as mecânicas que consagraram e singularizaram os trabalhos do designer Stefan Feld, observa-se um jogo que explora de maneira mais acentuada a temática medieval, no caso a Matéria da Bretanha, e os jogadores são levados ao mito arturiano clássico, assumindo o papel de cavaleiros que disputam a sucessão do trono do rei Artur. Quiçá esse acento temático seja resultado da parceria com Michael Rieneck, designer de jogos que valoriza a temática.

Em Merlin, acessam-se os principais elementos do mito arturiano propagado por diversas mídias, com a Távola Redonda sendo o centro do tabuleiro e principal espaço das ações dos jogadores, com abundantes referências ao universo cavaleiresco, com castelos, flâmulas, espadas, escudos, imagens de cavaleiros armados etc., com a Excalibur e o Santo Graal sendo itens do jogo, e com o próprio rei Artur. As ações do jogo, articuladas com as imagens, não trazem elementos da fantasia, e a mecânica consegue expressar a temática, por exemplo, com os jogadores expulsando os inimigos (traidores), construindo palacetes e cumprindo missões designadas pelo rei Artur.

\section{A invasão viking}

Invasores do mar do Norte (2015) e Um banquete a Odin (2016) são dois jogos relacionados com o universo escandinavo, particularmente com o que se convencionou chamar de civilização viking, uma das principais expressões do medievalismo desde o século passado. ${ }^{22}$ Sabe-se que a sociedade escandinava medieval conheceu diversas representações ao longo do tempo; porém, foi no século XIX que se moldaram os principais estereótipos relacionados com tais povos, que passaram a ser designados como vikings (LANGER, SANTOS, 2001). Entre os estereótipos, podem-se citar: o equipamento de guerra, com destaque para os capacetes com enormes chifres laterais, elemento que não oferece vestígio material para o medievo; a representação dos escandinavos como seres impiedosos, pagãos e cruéis; e a imagem de vikings bebendo cerveja e hidromel nos crânios inimigos (LANGER, 2002).

Langer (2002) pontua que tais estereótipos acabam circulando de maneira muito intensa entre o cinema, a televisão, a literatura e os quadrinhos. Outrossim, Silva e Albuquerque (2016) argumentam que tal circulação intensificou-se a 
partir do final da década de 1980, sendo perceptível a ampliação da presença da temática viking - deuses do panteão nórdico, criaturas mitológicas, releituras de eventos da Escandinávia pré-cristã - em obras ficcionais e artísticas. A temática ganhou novo impulso no século XXI, em especial com o lançamento do filme Thor (2011) e da série Vikings (2013), e esse contínuo crescimento do apelo midiático da Escandinávia medieval pode ser percebido no número de jogos de tabuleiro relacionados com o tema. Segundo os dados do site BoardGameGeek. com, constam 112 jogos ligados ao termo "viking”, e desse universo 88 jogos foram lançados após 2011.

Tal como outras produções culturais modernas, é possível notar a presença dos estereótipos citados nos jogos de tabuleiro. Invasores do mar do Norte, por exemplo, assim define a proposta do jogo no caderno de regras:

Invasores do Mar do Norte se passa nos anos centrais da era Viking. Como guerreiros Vikings, os jogadores buscam impressionar o Chefe da tribo saqueando populações desavisadas. Reúna uma tripulação, colete provisões e rume ao Norte para saquear Ouro, Ferro e Gado. Glória jaz em batalha, mesmo nas mãos das Valquírias. Portanto convoque seus guerreiros: é tempo de pilhar! (PHILLIPS, 2015, p. 2).

O caderno de regras é sucinto e não se preocupa em detalhar aspectos históricos e personagens da sociedade escandinava, ou o processo de criação do jogo. Apesar disso, há claramente a referência temporal à era viking e a mobilização de estereótipos, sendo o principal a questão da relação entre vikings e pilhagem/saque, elemento que garante pontos de vitória responsáveis pelo sucesso do jogador na partida.

Uma abordagem significativamente distinta aparece no jogo Um banquete a Odin. Nele, a pilhagem também se encontra presente; contudo, ela é apenas uma ação do jogo e não constitui elemento estruturante. A introdução do caderno de regras é esclarecedora sobre a compreensão da temática:

“Um Banquete a Odin” é uma saga em forma de jogo de tabuleiro. Você estará revivendo as conquistas culturais, expedições mercantis e pilhagem daquelas tribos conhecidas, nos dias de hoje, como "vikings" - um termo que era utilizado de maneira muito diferente durante o fim do primeiro milênio. Quando os nórdicos saíam para pilhar, eles costumavam dizer que 
estavam se encaminhando para uma "viking”. Seus antecessores escandinavos, no entanto, eram muito mais do que apenas piratas. Eles eram exploradores e fundadores de estados. [...] O motivo que impulsionava as pessoas dessa época a se tornarem grandes navegantes era a infeliz situação agrícola. O déficit de produção causava muita miséria. Neste jogo, você irá invadir e explorar novos territórios. E também irá vivenciar atividades diárias, como coletar recursos e alcançar uma posição financeiramente segura na sociedade. No fim, o jogador que tiver o maior valor em posses será declarado o vencedor (ROSENBERG, 2016, p. 1).

Nota-se o cuidado do designer e de sua equipe ${ }^{23}$ na definição histórica e contextual dos elementos do jogo, proporcionando um contato verossímil com o conteúdo histórico da Escandinávia medieval.

Figura 4 - Capa dos jogos Um banquete a Odin e Invasores do mar do Norte
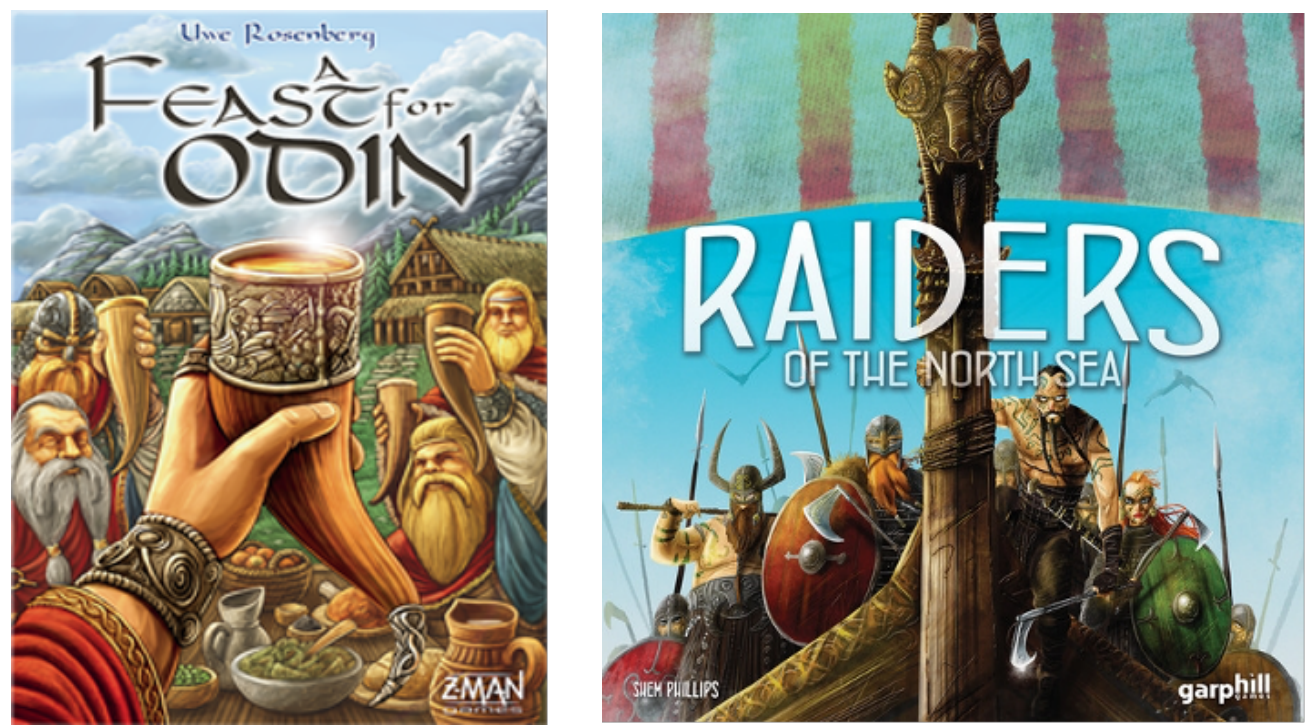

Fonte: à esquerda, https://www.ludopedia.com.br/jogo/a-feast-for-odin?v=imagens, acesso em 16/05/2020. À direita, https://www.ludopedia.com.br/jogo/raiders-of-the-north-sea?v=imagens, acesso em 16/05/2020.

Essa preocupação também se manifesta na capa do jogo Um banquete a Odin, que traz um grupo de homens em volta da mesa bebendo, sem qualquer menção a crânios ou capacetes com chifres. Se, por um lado, essa imagem remete aos cuidados na representação histórica do tema, a capa de Invasores do mar do Norte aponta novamente para a recepção contemporânea da Escandinávia medieval, com traços caricaturais e pinturas corporais que lembram os personagens da aclamada série Vikings (Figura 4). 


\section{O passado medieval em jogo}

Ao jogar um jogo, a maior parte da energia do jogador é gasta tentando usar as regras, os sistemas de jogo, para vencer. $\mathrm{O}$ contexto temático do jogo não deve prejudicar "o jogo em si", que significa buscar a vitória. [...] A configuração deve, portanto, ser extremamente simples, e deve ser conhecida pelos jogadores antes mesmo do jogo começar. Em bons romances e filmes, o enredo é usado para explicar o significado de um tema complexo. Em bons jogos, o tema claro está ali para ajudar os jogadores a criar a história (FAIDUTTI, 2017, p. 29). ${ }^{24}$

Os jogos de tabuleiro dessa última categoria distinguem-se por oferecer mais destaque aos elementos temáticos e cronológicos do que os jogos classificados por usar o período como pretexto. Todavia, não se deve sobrevalorizar tal aspecto, e, conforme os argumentos de Faidutti, a maior presença de elementos factíveis da sociedade medieval nesses jogos não constitui regras e uma jogabilidade imersiva, permanecendo a valorização da mecânica e a simplicidade em relação aos meandros históricos.

Figura 5 - Capa do jogo Viagens de Marco Polo

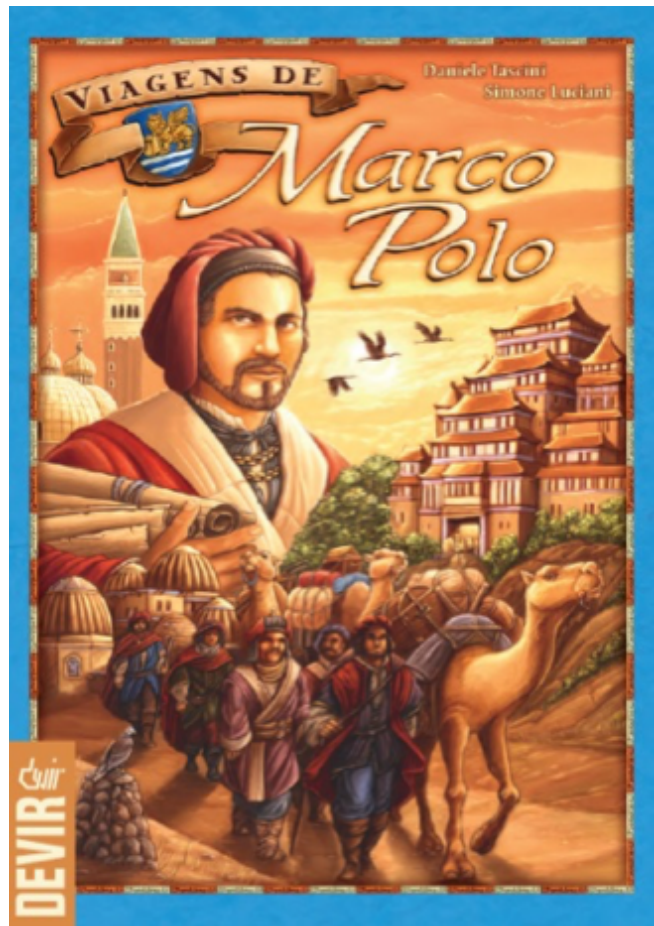

Fonte: https://www.ludopedia.com.br/jogo/ the-voyages-of-marco-polo? $\mathrm{v}=$ imagens, acesso em 16/05/2020.
O primeiro jogo a ser citado envolve um dos personagens históricos mais famosos da Idade Média, o jovem mercador italiano Marco Polo, que, em 1271, zarpou de Veneza em direção ao Oriente, tendo visitado várias cidades e o império mongol de Kublai Khan. Em Viagens de Marco Polo (2015), os jogadores recriam a jornada do viajante medieval, com cada jogador sendo um personagem que visitará as mesmas cidades alcançadas por Marco Polo. Os personagens do jogo-base são: Niccolo e Marco Polo, Matteo Polo, Guilherme de Rubruk, Mercador de Trabiz, Kublai Khan, Berke Kahn, Raschid ad-Din Sinan e Johannes Carpini. 
Diferentemente de Merlin, Viagens de Marco Polo afasta-se dos elementos maravilhosos relacionados com a narrativa de viagem e, explorando as mecânicas de alocação de dados e jogadores com habilidades diferentes, concentra-se nos aspectos factíveis da viagem. Outro ponto que diferencia o jogo é o tabuleiro, posto que, respeitando a história que aborda, concentra-se na Ásia, articulando o Mediterrâneo Oriental - tendo Veneza como limite a Oeste -, o Extremo Oriente e a África Oriental.

Ao observar a capa do jogo, nota-se o predomínio do cenário orientalizante, com destaque aos tons alaranjados e ao ocre, que prevalece (Figura 5). Por fim, por meio das cartas, Viagens de Marco Polo afasta-se dos clichês e dos estereótipos comumente associados aos povos orientais, mantendo um padrão na representação das localidades e dos personagens, com pouca variação nos tons de pele e na fisionomia.

Figura 6 - Capa do jogo Orléans e iluminura do século XIII
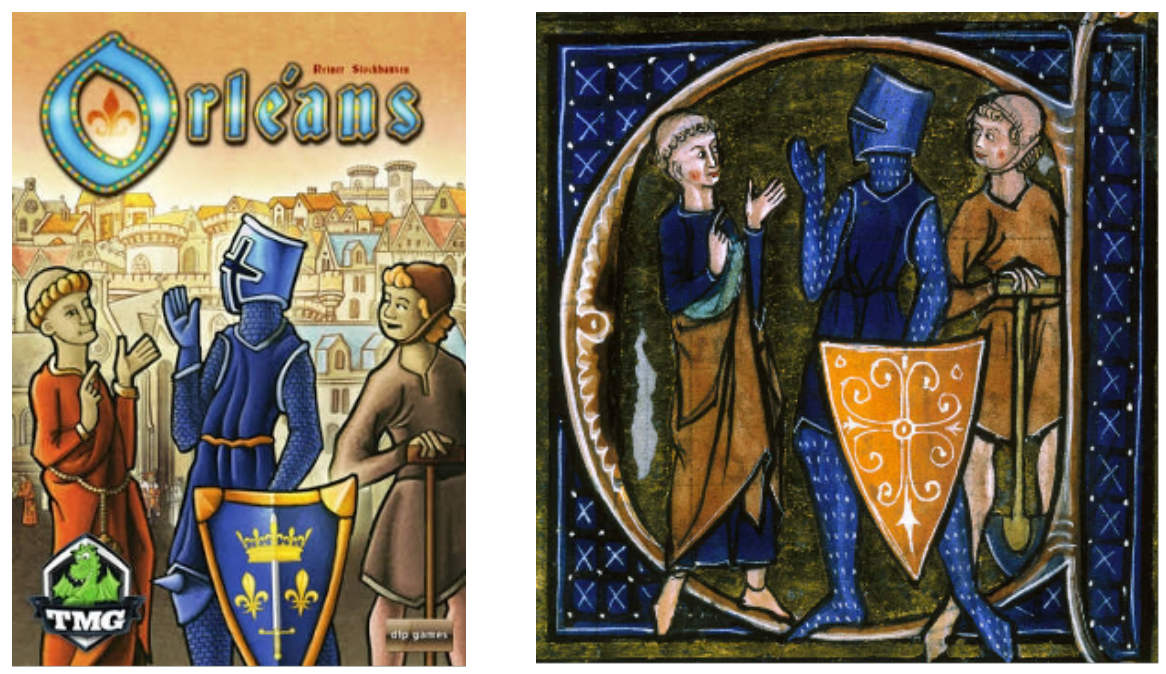

Fonte: à esquerda, https://www.ludopedia.com.br/jogo/orleans?v=imagens, acesso em 16/05/2020. À direita, Ms Sloane 2435, f.85. Cleric, knight and workman representing the three classes, illustration from "Li Livres dou Sante" (vellum). French School, (13th century). British Library, London, UK.

Muitos jogos de tabuleiro inspirados na Idade Média usam o nome de cidades, elemento que pode estar relacionado com o fato de as mecânicas privilegiadas por esses jogos serem de construção de edifícios, comércio e alocação de trabalhadores (MILLER, 2019). Esse é o caso de jogos como Carcassonne (2000), Córdoba (2008), Jerusalém (2010), Troyes (2010), Strasbourg (2011), Venetia (2013), Avignon (2016), entre tantos outros.

Do conjunto de jogos selecionados, um segue essa tendência: Orléans (2014). Ele se desenvolve na região do Loire, e cada jogador deve reunir grupos de agricultores, comerciantes, cavaleiros, monges e demais profissionais para expandir seus domínios. Ainda que o conteúdo do jogo não enfatize a questão 
das Três Ordens, a capa do jogo deixa essa referência clara, apropriandose da famosa imagem do século XIII, que representa o clérigo, o cavaleiro e o trabalhador (Figura 6). Ademais, em Orléans o tabuleiro do jogador (com referências a fazenda, castelo, scriptorium, monastério etc.) e as fichas de local (celeiro, vinícola, moinho, hospital etc.) oferecem muitos elementos que ampliam a questão temática do jogo.

Compondo a trilogia "Reino Ocidental”, de Shem Phillips e S. J. MacDonald, Arquitetos do reino ocidental (2018) e Paladinos do reino ocidental (2019) são os jogos mais recentes do levantamento. Ambos se passam na França medieval após o fim do Império Carolíngio, mais precisamente entre meados do século IX e inícios do século X. Arquitetos do reino ocidental acontece por volta do ano 850, e os jogadores assumem o papel de arquitetos francos competindo para impressionar o rei. Paladinos do reino ocidental se passa meio século depois, por volta de 900, explorando o contexto das invasões de sarracenos, vikings e bizantinos. Segundo o manual, os jogadores são nobres que "devem reunir trabalhadores da cidade para se defenderem contra inimigos, construir fortificações e espalhar a fé por toda a terra”.

As mecânicas dos jogos são similares, tornando-se mais complexa em Paladinos do reino ocidental. Considerando que, em geral, os jogos de tabuleiro costumam concentrar-se em personagens masculinos e enfatizar uma imagem homogênea da Idade Média, tendência também percebida na maior parte dos jogos analisados até o momento, merece destaque que ambos os jogos são cuidadosos nos traços, mantendo tons caricaturais comuns a todos os personagens, e promovem a diversidade dos personagens, em especial representando inúmeras mulheres em diferentes atividades (Figura 7).

Figura 7 - Cartas dos jogos Arquitetos do reino ocidental e Paladinos do reino ocidental
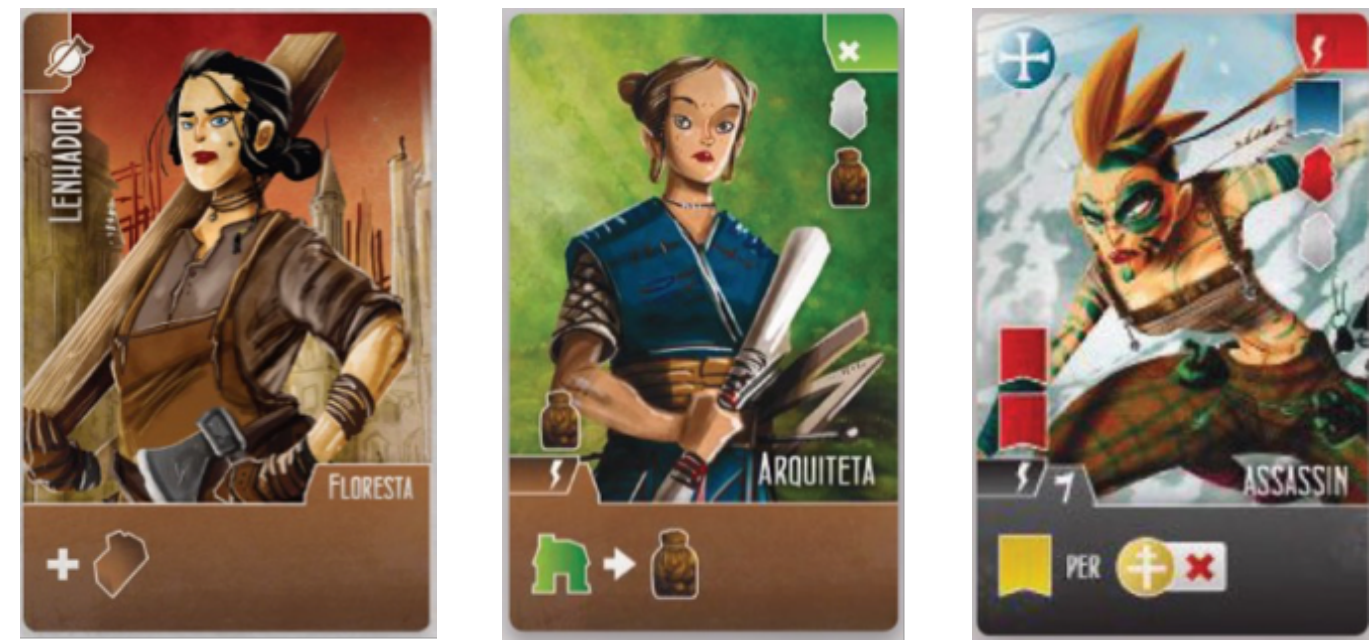

Fonte: à esquerda, Arquitetos do reino ocidental, Manual do jogador (2018, p. 3). Ao centro e à direita, Paladinos do reino ocidental, Manual do jogador (2019, p. 7, 20). 


\section{Idade Média, Idade dos Homens}

Em artigo recente, Bastos (2017) trouxe importantes questionamentos acerca da abordagem da Idade Média a partir da América Latina, problematizando quais parâmetros têm orientado e quais devem orientar tal produção. Na trilha dessa proposição, constata-se, entre os estudos medievais produzidos no Brasil, o crescimento das críticas à Idade Média eurocêntrica, estruturada em torno do padrão francês e em um único credo religioso, modelo que oferece pouco espaço para a diversidade étnica, religiosa e cultural do período. Ademais, começam a surgir abordagens que apontam para uma história global da Idade Média, valorizando as interações e as trocas culturais, em especial na bacia do Mediterrâneo (ALMEIDA, DELLA TORRE, 2019).

Essa outra Idade Média, que gradativamente avança no meio acadêmico, permanece distante dos jogos de tabuleiro. Nos jogos analisados, evidencia-se exclusivamente a associação entre Idade Média e Europa medieval, experiência europeia que, por vezes, é reduzida à Europa Central e, mais precisamente, às referências francesas e alemãs. Tal modelo se mostra em textos e imagens, os quais se relacionam, sobretudo, com as referências à vida rural - com destaque ao trabalho camponês - e à vida aristocrática - abordando o universo cavaleiresco, os castelos e o espaço cortesão. Essa referência é reafirmada, inclusive, pelos jogos que não oferecem indicações cronológicas ou espaciais precisas. Inserindo-se nesse modelo, mas representando um nicho à parte, nota-se a significativa presença da temática viking, que explora o sucesso midiático da Escandinávia pré-cristã.

Cabe considerar que, fora da seleção realizada, também é possível encontrar jogos “medievais” sobre o Oriente. Contudo, problemas similares aos apontados se repetem, com o Oriente sendo constantemente reduzido a referências ao dito Japão feudal, com uma abundância de samurais, e, no limite, à China. Como argumenta Faidutti (2017), ainda que a literatura mundial tenha absorvido as discussões pós-coloniais e os aportes de Edward Said acerca do orientalismo, não há nada disso nos jogos de tabuleiro, que permanecem representando o Oriente pelo "exotismo orientalista”. Para o autor:

Dê uma olhada nas caixas das centenas de jogos com "tema oriental” publicados todos os anos. Eles costumam olhar diretamente para fora de uma pintura de Guéricault, ou de uma popular enciclopédia geográfica dos anos cinquenta. $\mathrm{O}$ 
mundo árabe tem camelos, dunas de areia, comerciantes de seda ou especiarias, às vezes um djinn. [...] O mais marcante é provavelmente o Egito, um cenário muito popular, mas com basicamente apenas duas narrativas, construindo pirâmides e explorando pirâmides [...]. Quanto ao Egito moderno, ou mesmo ao Oriente moderno, para o que importa, está totalmente ausente dos jogos (FAIDUTTI, 2017, p. 14-15).

Outro aspecto que chama atenção e que resulta dos apontamentos anteriores é a falta de diversidade nos jogos de tabuleiro. No material analisado, os jogos estão centrados em figuras masculinas e brancas, por vezes desconsiderando a própria diversidade étnica da Europa medieval e a atuação das mulheres no período. Segundo Bethencourt (2018), esse modelo homogêneo para representar o europeu decorre da experiência iniciada com as grandes navegações, que gerou uma tensão entre a variedade cada vez maior de povos encontrados pelos europeus e a projeção de imagens estereotipadas nos povos africano, americano e asiático. Para o autor, essa tensão teve como resultado tanto a classificação das diferentes partes e povos do mundo quanto a definição dos europeus como genericamente brancos, desconsiderando os diversos estereótipos étnicos que existiam na Europa.

Especificamente sobre a questão da representatividade das mulheres, Tanya Pobuda (2018) expõe que as pesquisas sobre jogos de tabuleiro têm apontado que somente $5 \%$ dos jogos investigados apresentam apenas mulheres na capa, $5,8 \%$ apresentam um grupo de pessoas composto principalmente por mulheres e $62,5 \%$ tinham uma capa que mostrava apenas homens. O levantamento realizado pela autora nas capas dos jogos aponta que personagens brancos formam a maioria significativa, chegando a $83,7 \%$ do material analisado, ao passo que homens foram representados em 73,3 dos casos. Ademais, Pobuda sustenta que a falta de diversidade presente nos jogos também é constatada em meio aos designers (93,5\% são homens brancos) e às equipes de ilustração (81,2\% são homens brancos).

Esses apontamentos evidenciam outras faces da Idade Média lúdica dos jogos de tabuleiro, questões complexas, que ultrapassam as discussões particulares da medievalística e que convidam a novas investigações.

\section{Considerações Finais}

Simplificar e objetivar o passado tem obviamente menos 
consequências sociais e históricas do que simplificar, objetivar e até colonizar o resto do mundo, mas faz parte do mesmo estado de espírito. Orientalismo e exotismo histórico pertencem ao mesmo discurso intelectual, e acho a prevalência desse discurso nos jogos - mesmo quando é cada vez mais de forma distanciada e mais ou menos irônica - impressionante e um pouco inquietante (FAIDUTTI, 2017, p. 27).

Os jogos de tabuleiro modernos fazem parte de uma lucrativa indústria de entretenimento que cresce acentuadamente desde os finais do século passado. Tal como se observa em outras mídias, os jogos expressam o apelo da Idade Média no mundo contemporâneo. O mercado demanda produtos "medievais", e a indústria dos jogos têm oferecido um medievo rentável, que diverte e vende. Os jogos de tabuleiro estão carregados de referências medievais e evidenciam um medievo multifacetado, formado por referenciais acadêmicos, artísticos e midiáticos que se sobrepõem nos jogos.

Nos jogos analisados, é possível reconhecer alguns indícios recorrentes que remetem à representação da Idade Média nos jogos de tabuleiro. Por um lado, um medievo de acentuada presença do ambiente rural, de guerreiros e camponeses, aristocrático, cristão, violento, masculino e branco, de armas brancas e armaduras, do trabalho artesanal, de cidades amuralhadas com ruas estreitas e feirantes, um mundo anterior à Revolução Industrial, um tempo de alteridade; por outro lado, um medievo ligado à fantasia, repleto de seres fantásticos, de magias e feitiços, de mistérios e aventuras épicas, de monstros e forças sobrenaturais, da luta entre o bem e o mal, este que pode ser vencido por meio da bravura e da honra.

A caracterização do jogo de tabuleiro como “medieval” passa ainda por outros fatores, como o uso de nomes de cidades europeias, termos medievalizantes, como "paladino" e "reino", referências a deuses nórdicos e a construção de enredos em torno de figuras históricas, como Marco Polo, e ficcionais, como Merlin. Os jogos destacam-se, sobretudo, pela mobilização de um léxico visual pautado por edifícios, vestimentas, armas, objetos etc., iconografia que evoca a Idade Média presente no imaginário contemporâneo e que é constantemente retroalimentada pela cultura de massa, demonstrando as interfaces entre as representações presentes nos jogos de tabuleiros e em outras mídias. Nota-se ainda a constante sobreposição de elementos inspirados na realidade histórica, com referências ao medievalismo, construindo um medievo que apetece e gera 
lucro, sem demandar maiores aprofundamentos dos jogadores. Em síntese, a Idade Média nos jogos de tabuleiro é um verdadeiro caleidoscópio, com múltiplas imagens que, associadas, permitem reconhecer um jogo como medieval.

Finalmente, os jogos analisados permitem observar a centralidade ocupada pelo medievo europeu como principal referência acerca da Idade Média como um todo. Em outras palavras, é a Idade Média europeia, mais precisamente a cristandade do Ocidente medieval e, em parte, a Escandinávia pré-cristã, com seus mitos, personagens, instituições, entre inúmeras outras referências, que se generaliza como única Idade Média. Há ainda a predominância de um medievo masculino e guerreiro - seja pelas capas dos jogos, seja pelos próprios personagens que representam os jogadores -, que dá pouco espaço à diversidade. Em linhas gerais, os jogos de tabuleiro são mais uma expressão de uma Idade Média que ainda não foi descolonizada, um medievo homogêneo, tão perigoso para os dias atuais.

\section{Referências}

ABIKIER, Séverine; BESSON, Anne; PLET-NICOLAS, Florence (dir.). Le Moyen Âge en jeux. Pessac: Presses Universitaires de Bordeaux, 2009.

ALMEIDA, Néri d Barros; DELLA TORRE, Robson (org.). O Mediterrâneo medieval reconsiderado. Campinas/SP: Editora da Unicamp, 2019.

AMALVI, Christian. Idade Média. In: LE GOFF, Jacques; SCHMITT, Jean-Claude (dir.). Dicionário temático do Ocidente medieval. Bauru/SP: Edusc, 2006, v. I, p. 537551.

BASTOS, Mario Jorge da Motta. Estabelecidos e outsiders na medievalística contemporânea. Revista Ágora, Vitória, n. 26, 2017, p. 107-121.

BESSON, Florian; KIKUCHI, Catherine; TROADEC, Cécile. Les Moyen Âge de Game of Thrones. Cahiers de Recherches Médiévales et Humahistes, n. 28, 2014.

BETHENCOURT, Francisco. Racismos: das Cruzadas ao século XX. São Paulo: Cia das Letras, 2018.

BIRRO, Renan. Jogos eletrônicos e medievalismo: reflexões e críticas na educação brasileira. In: BIRRO, R. et al. Aprendendo história: ensino \& medievo. União da Vitória: Edições Especiais sobre Ontens, 2019.

BORIT, Cornel; BORIT, Melania; OLSEN, Petter. Representations of colonialism 
in three popular modern board games: Puerto Rico, Struggle of empires and Archipelago. Open Library of Humanities, v. 4(1), n. 17, p. 1-40, 2018.

BRAND, Inka; BRAND, Markus. Village - livro de regras. s/l. Eggertspiele, 2007.

CARPEGNAFALCONIERI,Tommaso di.Médiéval et militant.Penserle contemporain à travers le Moyen Âge. Paris: Publications de la Sorbonne, 2015.

CRAMER, Michael. Reenactment. In: EMERY, Elizabeth; UTZ, Richard (ed.). Medievalism: key critical terms. Cambridge: D. S. Brewer, 2014 [ebook].

ECO, Umberto. Sobre os espelhos e outros ensaios. Rio de Janeiro: Nova Fronteira, 1989.

ELLIOT, Andrew. Medievalism, politics and massa media: appropriating the Middle Ages in twenty-first century. Cambridge: D. S. Brewer, 2017.

EMERY, Elizabeth; UTZ, Richard. Making medievalism: a critical overview. In: EMERY, Elizabeth; UTZ, Richard (ed.). Medievalism: key critical terms. Cambridge: D. S. Brewer, 2014 [ebook].

FAIDUTTI, Bruno. Postcolonial Catan. Analog Game Studies, v. 2, p. 3-34, 2017.

FERRÉ, Vincent (dir.). Médiévalisme: modernité du Moyen Âge. Itinéraires, Littérature, textes, cultures [en ligne], 2010-3, 2010.

GUITON, Raphaël, LULLIEN, Jean-Baptiste, RAOULT, Nicolas. Zombicide: black plague. Livro de regras e missões. s/l. Galápagos Jogos, 2015.

HAYDOCK, Nickolas. Movie medievalism. The imaginary Middle Ages. North Carolina: McFarland \& Company, 2010.

JIMÉNEZ ALCÁZAR, Juan Francisco. De la Edad Media de los imperios a la guerra total: medievo y videojuegos. Madri: Compobell, 2016. Colección Historia y Videojuegos, n. 3.

JUUL, Jesper. The game, the player, the world: looking for a heart of gameness. In: COPIER, Marinka; RAESSENS, Joost (ed.). Level Up: Digital Games Research Conference Proceedings. Utrecht: Utrecht University, 2003.

KAUFMAN, Amy S. Medieval unmoored. Studies in Medievalism, v. XIX, 2010.

KLINE, Daniel. Participatory medievalism, role-playing, and digital gaming. In: D'ARCENS, Louise (ed.). The Cambridge Companion to Medievalism. Cambridge: 
Cambridge University Press, 2016 [ebook].

LANGER, Johnni. Os vikings e o estereótipo do bárbaro no ensino de história. História \& Ensino, Londrina, v. 8, p. 85-98, out. 2002.

LANGER, Johnni; SANTOS, Sérgio Ferreira dos. Fúria odínica. A criação da imagem oitocentista sobre os vikings. Varia Historia, Belo Horizonte, n. 25, p. 214-230, jul. 2001.

MACEDO, José Rivair. Introdução. Cinema e Idade Média: perspectivas de abordagem. In: MACEDO, J. R.; MONGELLI, L. M. (org.). A Idade Média no cinema. São Paulo: Ateliê Editorial, 2009. p. 13-48.

MASTEY, David. Slave play, or the imperial logic of board game narrative. Caribbean Quarterly, v. 65, n. 3, p. 367-387, 2019.

MATTHEWS, David. Medievalism: a critical history. Cambridge: D. S. Brewer, 2015 [ebook].

MILLER, Timothy S. Bidding with Beowulf, dicing with Chaucer, and playing poker with King Arthur: neomedievalism in Modern board-gaming culture. Studies in Medievalism, v. XXIX, p. 149-175, 2019.

MUCENIECKS, André S. Notas sobre o termo viking: usos, abusos, etnia e profissão. Revista Alethéia, v. 2, n. 2, ago./dez. 2010.

NASCIMENTO, D. B. P. Idade Média: contexto, celtas, mulher, Carmina Burana e ressurgências atuais. Niterói: Parthenon Centro de Artes e Cultura, 2015.

PALOMAR MILLÁN, Germán. Los juegos de mesa. Creación y producción. Granada: Universidad de Granada, 2012.

PHILLIPS, Shem. Invasores do Mar do Norte - manual. s/l. Meeple BR Jogos, 2015. POBUDA, Tanya. Assessing gender and racial representation in the board game industry. Analog Games Studies, v. 5, 2018. Disponível em: http:// analoggamestudies.org/2018/12/assessing-gender-and-racial-representationin-top-rated-boardgamegeek-games/ último acesso em 13/05/2020.

PORTO JÚNIOR, J. B. S. As expressões do medievalismo no século XXI. In: Anais do Encontro Internacional e XVIII Encontro de História da Anpuh-Rio. Rio de Janeiro, 2018. 
ROBINSON, Will. Orientalism and abstraction in eurogames. Analog Games Studies, v. 1, p. 55-63, 2016.

ROCHEBOUET, Anne; SALOMON, Anne. Les réminiscences médiévales dans la fantasy.Un mirage des sources?.Cahiers de Recherches Médiévalistes et Humanistes, n. 16, 2008.

ROSENBERG, Uwe. Um banquete a Odin - livro de regras. s/l. Mandala Games, 2016. SILVA, Danielle Gallindo; ALBUQUERQUE, Maurício da Cunha. Para uma recepção do medievo: a temática viking no heavy metal. Revista de História Comparada, Rio de Janeiro, v. 10, n. 1, p. 230-261, 2016.

TORNER, Evan; TRAMMELL, Aaron; WALDRON, Emma L. Reiventing analog game studies: introductory manifesto. Analog Game Studies, v. 1, 2016.

TRAXEL, Oliver. Medieval and pseudo-medieval elements in computer roleplaying games: use and interactivity, Studies in Medievalism, v. XVI, p. 125-142, 2008.

VACCARINO, Donald. Dominion - manual. s/l. Rio Grande Games. 2008.

VIVEIROS, Guillaume. Passé ludique et déviations historiques. Sens et fonction du Moyen Âge dans les jeux de rôle. Ottawa: Université d'Ottawa, Maîtrise en histoire, 2017.

WADA, E. K.; MORETON, F. A.; NASCIMENTO, T. F.; MOREIRA, A. G. O medievalismo em eventos no Brasil. Revista Turismo \& Desenvolvimento, n. 21/22, 2014.

WHITEHILL, Bruce. American games: a historical perspective. Board Games Studies, p. 116-141, 1992.

WILSON, Devin. The eurogame as heterotopia. Analog Game Studies, v. II, p. 4349, 2017.

WOODS, Stewart. Eurogames. The design, culture and play of modern European board games. North Carolina: McFarland \& Company, 2012.

\section{Notas}

${ }^{1}$ Professor de História Antiga e Medieval da Universidade Federal do Oeste do Pará (Ufopa). Doutor (2016) e mestre (2012) pelo Programa de Pós-Graduação em História da Universidade Federal Fluminense (UFF). Coordenador do "Legatio: Grupo de Pesquisa, 
Ensino e Extensão em História Medieval e Ensino de História”. E-mail: douglas.mxl@ ufopa.edu.br.

${ }^{2}$ Em levantamento realizado no Diretório de Grupos de Pesquisa no Brasil, do CNPq, foram identificados quatro grupos relacionados com o tema do medievalismo, dois em Letras e dois em História, respectivamente: Estudos de Residualidade Literária e Cultural/UFC; Linguística Histórica/UFMG; Laboratório de Estudos sobre a Transmissão e História Textual na Antiguidade e no Medievo/LETHAM-UFBA; Núcleo de Estudos sobre Narrativas e Medievalismos/LINHAS-UFRRJ. Disponível em: http://dgp.cnpq.br/ dgp/faces/consulta/consulta_parametrizada.jsf, último acesso em 22/04/2020.

3"...] representa en todo momento lo intangible y el universo de las más irracionales creencias y comportamientos humanos. La brujería, la magia, la brutalidad, el amor cortés (el caballero y la dama), lo fantástico de una arquitectura imaginada (castillos en ruinas completados en las mentes de las gentes del XIX y, en consecuencia, de nosotros, hombres y mujeres del XXI) o no (fortalezas espléndidas que enseñorean el paisaje europeo), armas señal de dignidad (grandes espadas), heráldica y genealogía como atractivo per se...; la percepción de una categoria y comportamiento social (un señor feudal tiene hoy una imagen colectiva muy definida, al margen de su realidad, al igual que un vasallo)... hasta la gastronomía posee su espacio en ese universo (una cena medieval se asocia a una deglución sin medida y pantagruélica)" (JIMÉNEZ ALCÁZAR, 2016, p. 80). Para facilitar a leitura do texto, no corpo do artigo serão apresentadas traduções livres dos trechos, e em notas de rodapé, a versão original da publicação. Esse padrão será seguido em todo o artigo.

${ }^{4}$ No presente estudo, a expressão jogo de tabuleiro será usada para caracterizar jogos que utilizam superfícies planas, por isso chamados jogos de mesa e jogos de carta. Não serão considerados jogos de carta colecionáveis, como Magic, e jogos de RPG.

${ }^{5}$ Conhece-se apenas o trabalho de Miller (2019).

"Medieval games often have themes or storylines set in Europe or Asia, between the 5th century (476, the fall of the Western Roman Empire) and the 16th century (1492, the beginnings of European overseas colonization)" https://boardgamegeek.com/boardgamecategory/1035/ medieval, acesso em 20/04/2020.

${ }^{7}$ No ranking, constam duas versões do jogo Dominion, a versão-base, lançada em 2008, e a expansão, lançada em 2009. Como a expansão "Intrigue" apenas adiciona algumas cartas e define regras para o jogo com oito jogadores, as versões serão consideradas em bloco, e não individualmente. Assim, as duas entradas somam apenas uma.

${ }^{8}$ https://www.ludopedia.com.br/tema/21, acesso em 20/04/2020.

${ }^{9}$ No ranking, constam as duas edições do jogo Dominion, a primeira, lançada em 2008, e a segunda, lançada em 2016. Visto que a diferença entre as edições é pontual (substituição de algumas cartas, inclusão de outras e adequação do texto), os jogos serão considerados em bloco. Assim, as duas entradas somam apenas uma.

10"1) Rules: Games are rule-based. 2) Variable, quantifiable outcome: Games have variable, quantifiable outcomes. 3) Value assigned to possible outcomes: That the different potential outcomes of the game are assigned different values, some being positive, some being negative. 4) Player effort: That the player invests effort in order to influence the outcome. (I.e. games are challenging.) 5) Player attached to outcome: That the players are attached to the outcomes of the game in the sense that a player will be the winner and 'happy' if 
a positive outcome happens, and loser and 'unhappy' if a negative outcome happens. 6) Negotiable consequences: The same game [set of rules] can be played with or without reallife consequences" (JUUL, 2003, s/p).

${ }_{11}$ "The nature of such games is that they are played by particular groups of people and thus lend themselves to the development of cultural formations which reflect both the moment in which they are produced and the identity and recreational choices of the players. This historical, cultural and economic context cannot be ignored in considering any categorization" (WOODS, 2012, p. 17).

${ }^{12}$ Sobre os american games, ver o estudo de Whitehill (1992) e a obra de Woods (2012).

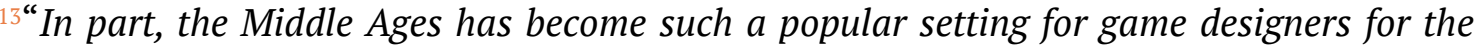
simple reason that no one owns King Arthur, as it were. As a kind of public domain 'megatext,' medieval settings and stories such as the Arthurian legends come with free built-in consumer recognition in a market where lucrative licenses for the rights to make games tied to popular media-franchises are enormously expensive but fiercely fought over, particularly such marquee properties as Star Wars, Star Trek, The Lord of the Rings, Game of Thrones, and Marvel and DC's superheroes, in addition to any number of less high-profile properties" (MILLER, 2019, p. 155).

${ }^{14}$ Disponível em: https://forbes.com.br/colunas/2019/07/mercado-de-jogos-detabuleiro-ganha-espaco-no-brasil/ último acesso em 26/04/2020.

${ }^{15}$ Disponível em: https://medium.com/deathmatch/o-mercado-de-board-games-nomundo-com-valores-69fa103e1d24 último acesso em 26/04/2020.

${ }_{16}$ "The fantasy idea we have of some historical periods is not very diferente from the fantasy idea we have, or had, of other parts of the world. Far away times are like far away places naive, simple, vaguely perverse and, of course, backwards. [...] While plain orientalism as described by Said is probably receding, or at least is dissected and discussed in universities, historical exoticism is still strong, mostly because there can be no 'post-medievalist' or 'postantiquist' backlash like there was a postcolonial one. [...] So the real issue is not orientalism, but exoticism as a whole, in geography and history, and why it is so prevalent in boardgames, much more than in books or movies, much more than in video games, and so insistently unsubtle. [...] For the game designer, India or China, Middle Ages or Antiquity, are not geographical places or historical times, they are just topoi, sets of standard references, which must not be more sophisticated than those mastered by the player. [...] As a result, he makes heavy use of orientalist, 'medievalist' or 'antiquist' clichés" (FAIDUTTI, 2017, p. 27-29).

${ }^{17}$ Meeples são pequenos bonecos em forma de pessoa usados como componentes em jogos de tabuleiro.

${ }^{18} \mathrm{~A}$ classificação ocorre apenas em ludopedia.com.br.

${ }_{19}$ “Au cinéma, en bande dessinée, en librairie, le Moyen Âge connaît un ample succès dont l'une des manifestations les plus importantes est incontestablement l'explosion de la fantasy, un sous-genre paralittéraire assez récent qui le plus souvent fait évoluer ses personnages dans un univers imaginaire proche, ou tout au moins inspiré, du Moyen Âge. [...] Dans ce royaume des mondes qui n'existent pas, le lecteur se trouve confronté à un Moyen Âge qui n'existe pas, ou plutôt à un mirage. [...] Genre aux frontières floues et, selon les oeuvres, à la limite du littéraire et du paralittéraire, la fantasy fournit un corpus qui permet de façon privilégiée d'examiner cette oscillation entre la représentation d'un Moyen Âge rêvé et revisité 
et la convocation, parfois, d'un véritable savoir érudit" (ROCHEBOUET, SALOMON, 2008, p. 320).

20"not a dream of the Middle Ages, but a dream of someone else's medievalism. It is medievalism doubled up upon itself” (KAUFMAN, 2010, p. 4).

${ }_{21}$ "If medievalism can be said to work within a framework of distance (reverential or otherwise), then neomedievalism obliterates distance in an intensified combination of love and loathing, its desire for the past torn asunder between the denial of history and a longing for return. [...] Neomedievalism finds a way of clinging to the past by rejecting the 'history', the alterity, the time and space that separated it from its desired object and bringing it into the present. But what initially appears to be neomedievalism's denial of history may, instead, be a desire for history alongside the uncomfortable suspicion that there is no such thing. Neomedievalism consumes the Middle Ages in fragmented, repetitive tropes as a way of ensuring against loss" (KAUFMAN, 2010, p. 2-3).

${ }^{22} \mathrm{O}$ termo "viking" é comumente usado de maneira generalista e anacrônica, com conotações étnicas, para designar os povos escandinavos anteriores à cristianização. Tal associação remonta à sociedade oitocentista e foi consolidada com a cultura de massa do século XX, sendo carregada de anacronismo. Para Muceniecks (2010), conforme os vestígios documentais, seria mais seguro empregar o termo como sinônimo de pirataria, no sentido de uma ocupação, excluindo-se as conotações étnicas.

${ }^{23}$ De acordo com o livro de regras, Gernot Köpke foi o responsável pelos textos históricos, os quais foram complementados por Uwe Rosenberg.

${ }^{24}$ "When playing a game, most of the player's energy is spent in trying to use the rules, the game systems, in order to win. The thematic setting of the game must not detract from 'the game itself', meaning from aiming at victory. [...] The setting must therefore be extremely simple, and must be known by the players before the game even starts. In good novels and movies, the storyline is used to explain the meaning of a complex theme. In good games, the light theme is here to help the players create the story" (FAIDUTTI, 2017, p. 29).

${ }_{25}$ "Have a look at the boxes of the hundreds of 'oriental themed' games published every year. They usually look directly out either of a Guéricault painting, either of a popular geographic encyclopedia from the fifties. The Arab world has camels, sand dunes, silk or spice merchants, sometimes a djinn. [...] The most striking is probably Egypt, a really popular setting but with basically only two narratives, building pyramids and exploring pyramids [...]. As for modern Egypt, or even modern Orient for what matters, it is totally absent from games" (FAIDUTTI, 2017, p. 14-15).

${ }_{26}$ "Simplifying and objectifying the past has obviously fewer social and historical consequences than simplifying, objectifying and even colonizing the rest of the world, but it's part of the same frame of mind. Orientalism and historical exoticism belong to the same intellectual discourse, and I find the prevalence of this discourse in games - even when it's more and more often in a distanced and more or less ironic way - impressive, and a bit unsettling" (FAIDUTTI, 2017, p. 27). 